\title{
The effects of welding current and purging gas on mechanical properties and microstructure of tungsten inert gas welded aluminum alloy $5083 \mathrm{H} 116$
}

\author{
${\text { Ekak } \text { Novianto }^{1 *} \text {, Priyo Tri Iswanto }}^{1}$, and Mudjijana Mudjijana ${ }^{1}$ \\ ${ }^{1}$ Universitas Gadjah Mada, Department of Mechanical \& Industrial Engineering, Faculty of Engineering, Jalan Grafika No.2 Yogyakarta \\ 55281.
}

\begin{abstract}
Aluminum alloy $5083 \mathrm{H} 116$ has an exceptional performance in extreme environments, moderately high strength, outstanding corrosion resistance in salt water and high impact strength at cryogenic temperature. In the present study, Aluminum alloy AA $5083 \mathrm{H} 116$ plates were joined by tungsten inert gas (TIG) process by single and double sided welding. Welding current used was $53 \mathrm{~A}$ and $80 \mathrm{~A}$ with the addition of purging gas during welding process. The effects on micro structure and mechanical properties like surface hardness and tensile strength of the welded region were studied. The results have shown that optimum current out of the two weld current used is $53 \mathrm{~A}$. Better microstructures, tensile and hardness were found in the welded joint for the weld current $53 \mathrm{~A}$ where the tensile obtained in the softened zone was approximately $87 \%$ than that of the base metal (BM). With increasing of TIG current, the width of PMZ increased. In addition, the doubled sided welding sequence also produced broader PMZ area.
\end{abstract}

\section{Introduction}

Tungsten inert gas (TIG) is an arc welding process where heat is generated between base metal and tungsten electrode. The heat of arc is high enough to melt the base metal and generates weld pool due to the inert gas. TIG welding process, which was demonstrated first in 1930, is suitable for joining different material with high quality weld bead [1-2]. No flux is needed in this welding process because the inert gas could prevent the oxidation of molten aluminum.

Known for its excellence performance in extreme environments, retaining high strength after welding process and having the highest strength for non-treatable alloy, aluminum alloy 5083 is widely used in modern shipbuilding and train industries. [3-4]. However, low strength of welding joint, high porosity in welding area and large deformation after welding are the challenges in welding the 5038 aluminum alloy [5-6].

Vinod [7] have examined the effect of welding current, gas flow rate and groove angle on weld bead and found that compared to the other parameters, welding current was the most significant factor. The other investigation [8] has studied the influence of TIG welding parameter in order to obtain the highest tensile strength and minimum distortion of stainless steel. From the research it could be concluded that the most important parameter that affects distortion is welding current. The effect of welding current on the shape of bead, structural and mechanical properties of stainless steel which is joined with tungsten inert gas welding have investigated by Kumar et al. [9]. They found that welding current affects the bead width, microstructure and hardness of welded joint [9].

Welding sequence of operations also can affect the quality of the joints. An investigation of welding sequence and direction on mechanical properties of friction stir welding process using aluminum has been done by Kumar et al. They argued that compared to opposite directional weld, double sided same direction weld has better tensile properties. They also found that direction of welding in opposite direction weld does not affect the hardness of the joint. If the welding zones are accessible from both sides, the double sided welding with one direction of tool movement showed the best results [10].

The effect of welding current, welding sequence and the addition of purging gas on tensile strength, hardness and morphology of aluminum alloy $5083 \mathrm{H} 116$ that is welded by tungsten inert gas process was investigated in present work. Full factorial design is used in order to find out the optimum results of all parameters. Not only the parameters but also their interactions will be discussed in this paper.

\section{Methodology}

Aluminum alloy $5083 \mathrm{H} 116$ in form of rolled sheet was cut into plates with dimension of $300 \mathrm{~mm} \times 150 \mathrm{~mm} \times 3$ $\mathrm{mm}$. ER 5356 welding rod with a diameter of $2.4 \mathrm{~mm}$ was used as filler metal. Table 1 and table 2 shows the chemical composition of base metal and the filler metal, respectively.

* Corresponding author: ekakn@ymail.com 
Table 1. Chemical composition of AA 5083 H116.

\begin{tabular}{|c|c|}
\hline Element & Weight (\%) \\
\hline $\mathrm{Si}$ & 0,18 \\
\hline $\mathrm{Fe}$ & 0,31 \\
\hline $\mathrm{Cu}$ & 0,042 \\
\hline $\mathrm{Mn}$ & 0,60 \\
\hline $\mathrm{Mg}$ & 4,76 \\
\hline $\mathrm{Zn}$ & 0,15 \\
\hline $\mathrm{Cr}$ & 0,086 \\
\hline $\mathrm{Ti}$ & 0,013 \\
\hline $\mathrm{Ni}$ & 0,0074 \\
\hline
\end{tabular}

Table 2. Chemical composition of the ER 5356 filler material.

\begin{tabular}{|c|c|}
\hline Element & Weight (\%) \\
\hline $\mathrm{Si}$ & 0.25 \\
\hline $\mathrm{Fe}$ & 0.40 \\
\hline $\mathrm{Cu}$ & 0.10 \\
\hline $\mathrm{Mn}$ & $0.05-0.20$ \\
\hline $\mathrm{Mg}$ & $4.5-5.5$ \\
\hline $\mathrm{Zn}$ & 0.10 \\
\hline $\mathrm{Cr}$ & $0.05-0.20$ \\
\hline $\mathrm{Ti}$ & $0.06-0.20$ \\
\hline $\mathrm{Al} \mathrm{min.}$ & Rem \\
\hline
\end{tabular}

Table 3. Design of experiment.

\begin{tabular}{|l|c|c|c|}
\hline Sample & $\begin{array}{c}\text { TIG Welding } \\
\text { Current (A) }\end{array}$ & $\begin{array}{c}\text { Purge (P)/ No } \\
\text { Purge (NP) }\end{array}$ & $\begin{array}{c}\text { One Side (OS)/ } \\
\text { Double Side (DS) }\end{array}$ \\
\hline 53OS-NP & 53 & NP & OS \\
\hline 53DS-NP & 53 & NP & DS \\
\hline 53OS-P & 53 & P & OS \\
\hline 53DS-P & 53 & P & DS \\
\hline 80OS-NP & 80 & NP & OS \\
\hline 80DS-NP & 80 & NP & DS \\
\hline 80OS-P & 80 & P & OS \\
\hline 80DS-P & 80 & P & DS \\
\hline
\end{tabular}

Two different values of welding current (53 Ampere and 80 Ampere) are used to investigate the effect of current on aluminum alloy $5083 \mathrm{H} 116$ square joint with TIG welding. Fig. 1 shows the welded specimen. Besides, the sequence of operations is also used as welding parameter. The specimens were joined using single and double sided welds. The purging gas was added in the other side of welding (Fig. 2). Table 3 shows the design of experiment.

In order to get rid of surface contamination i.e. dust, rust and oil, the entire samples were mechanically and chemically cleaned by using acetone before welding process. No preheat or post heat was applied on the welding specimen. In order to make sure the good quality of welding products, the joint of welded samples were visually inspected. It is verified that there is no presence of holes, porosity or the other visible defects on welded joint samples.
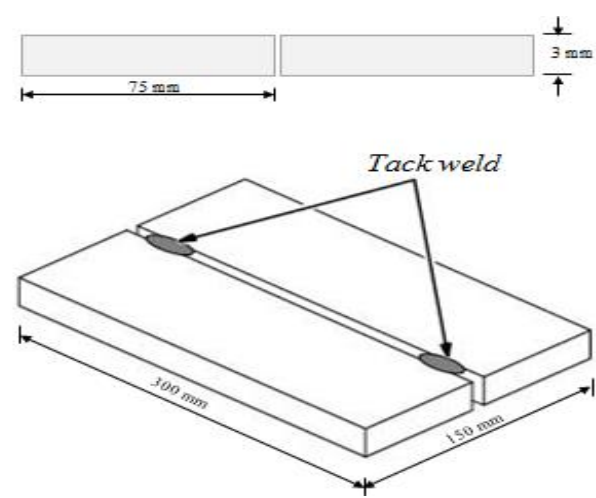

Fig. 1. The welded specimen.

(a)

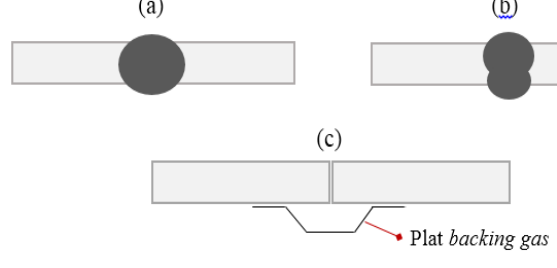

Fig. 2. The sequence and method of welding: (a) one-side welding, (b) double side welding and (c) plat backing gas.

\section{Results and discussions}

\subsection{Tensile properties}

The effects of welding current, welding sequence and the addition of purging gas on the ultimate tensile strength (UTS) of the TIG welded joints are illustrated in Fig. 3. It is shown that the tensile strength of welded joint decreases with the increasing of welding current. The maximum strength of welded joints is achieved when the welding current was $53 \mathrm{~A}(316 \mathrm{MPa})$ which is $87 \%$ of that of the base metal. If the current is increased into $80 \mathrm{~A}$, the strength of the joint was started to decrease. This is due to the higher heat produced by $80 \mathrm{~A}$ compared to $53 \mathrm{~A}$ causing wider softening area.

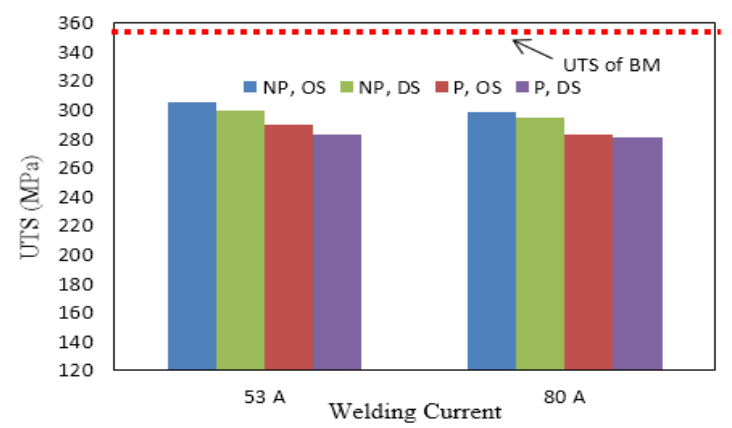

Fig. 3. The tensile strength of welding joints with different welding current, welding sequence and the addition of purging gas.

Welding sequence also affected the tensile properties of welded joint. One side welding sequence is slightly better than the double sided one. The UTS value of the welded joint with double side sequence at $53 \mathrm{~A}$ was 306

\footnotetext{
*Corresponding author: ekakn@ymail.com
} 
$\mathrm{MPa}$, which decreased only $3 \%$ of that the welded joint with one side sequence at the same welding current. In addition, the decreasing of UTS value for the sample at 80 A with double sequence was only $1.3 \%$ compared to the one side one. This phenomenon may be due to the heat addition effects of the two pass welding.

The tensile strength of welded joint decreased with the addition of purging gas. The strength of the welded joint with the addition of purging gas for one side sequence at 53 A was $290 \mathrm{MPa}$, which decreased $10 \%$ of that of the welded joint without purging gas at the same welding current and welding sequence. The same phenomena is also happen for one side sequence at $80 \mathrm{~A}$ where the addition of purging gas decreased the tensile properties of weld joint up to $5 \%$ compared to the weld joint without purging gas because argon offers more available heat than ambient air.

\subsection{Micro-hardness}

The area of heat affected zone (HAZ) and partially melted zone (PMZ) could be discovered when micro-hardness of welded joint was measured. This measurement could represent the changing in microstructure of welding area. Fig 4 shows the micro-hardness distribution with different TIG current. From the figure it can be summarized that the hardness of welding joints decreased with the increasing of TIG current. There is a decreasing of $6.62 \%$ for the lowest hardness in welded area. The PMZ area of $80 \mathrm{~A}$ specimen is wider than $53 \mathrm{~A}$ specimen means that $80 \mathrm{~A}$ specimen has broader weak area. It could be also said that the increasing of TIG current broaden the area of softened zone because of higher heat input causing coarse PMZ grain and then decreasing the hardness in PMZ [11].

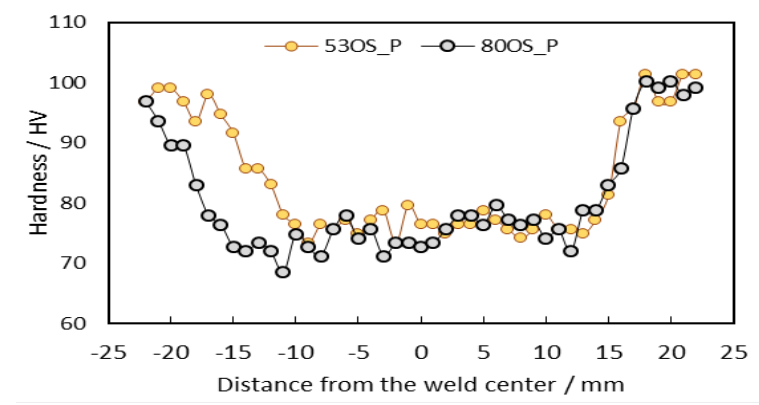

Fig. 4. Hardness distribution with different TIG current.

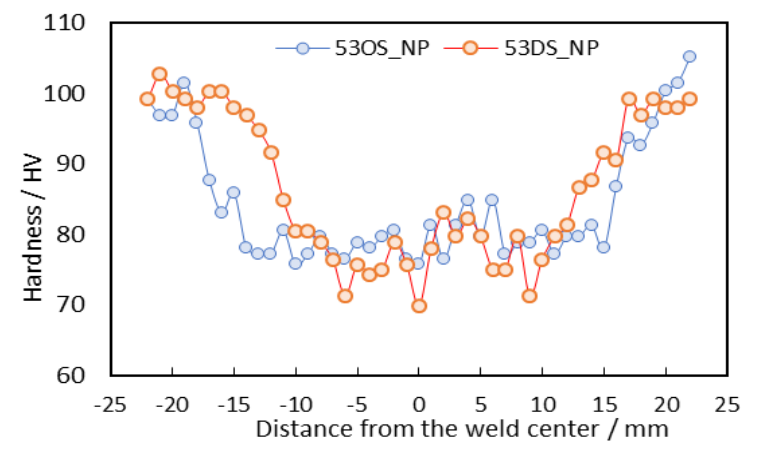

Fig. 5. Hardness distribution with different welding sequence.
The effect of welding sequence on micro-hardness of aluminum alloy joint with tungsten inert gas welding is illustrated in Fig. 5. It could be summarized that welding sequence affects the hardness of welded joint eventhough it is not significant. Generally, the hardness of welded and $\mathrm{HAZ}$ area of double sided welding is lower than one side welding because the double sided welding absorbed more heat than the one sided welding [12].This is supported by the tensile result where one side welding specimen has higher ultimate tensile strength than the double sided one based on the results, the hardness of purging specimen and without purging specimen showed the same trend and closed values (Fig. 6). In general, the hardness of HAZ and weld zone of purge specimen is higher than that of no purge one due to coarsened grain size produced by slower heat dispersed of argon.

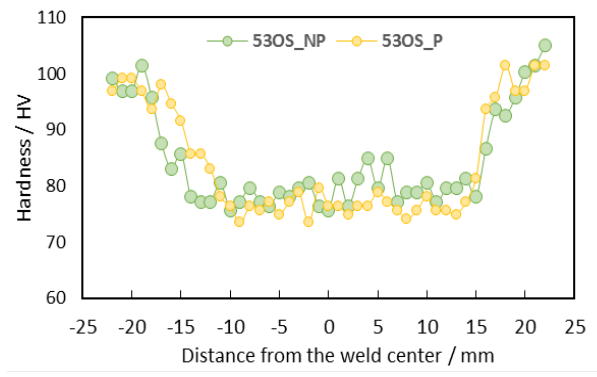

Fig. 6. Hardness distribution with the addition of purging gas.

\subsection{Microstructure}

The morphology of welded specimen was observed in order to differentiate three different zones of the joint, i.e. weld metal (WM), partially melted zone (PMZ) and heataffected zone (HAZ). The width of partially melted zone increased with the increasing of welding current. In addition, the doubled sided welding sequence also produced broader PMZ area. These results supported the tensile and hardness results where both the lower current and one side welding sequence generated higher tensile and hardness.
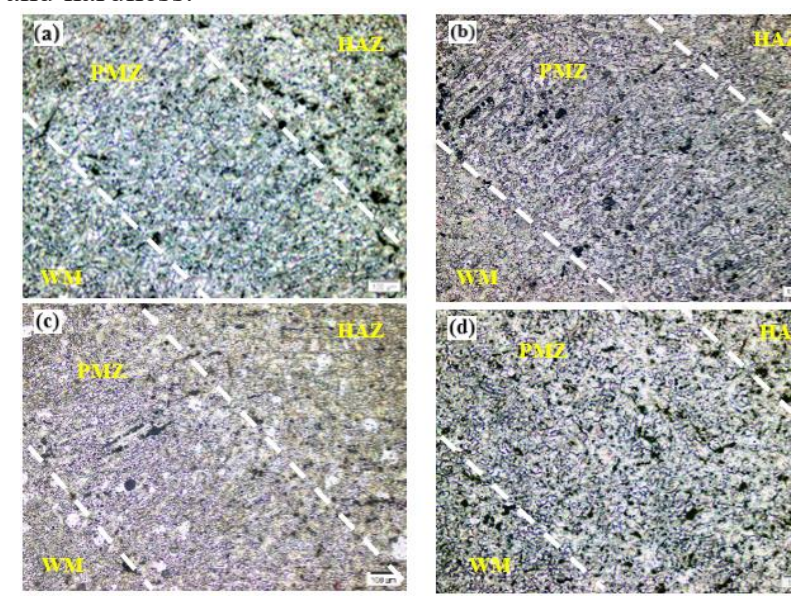

Fig. 7. Microstructure change with welding parameter.

Fig. 8 shows microstructure of different zones of joint for $53 \mathrm{~A}$, double sided and without purging gas specimen. It is cleared that different grain size represent different

\footnotetext{
*Corresponding author: ekakn@ymail.com
} 
area of the joint. The grain size of HAZ is the largest compared to the other zones causing HAZ as the weakest point in terms of strength and hardness (Fig. 8b). Due to longer dwell time exposed to HAZ than PMZ, the grain in HAZ had enough time to grow causing larger grain size. The grain structure in PMZ is columnar (Fig. 8d) and coarser than the weld metal. The grain structure of weld metal (Fig. 8c) is uniform and smooth leading to highest strength and hardness compared to the other welding zones.

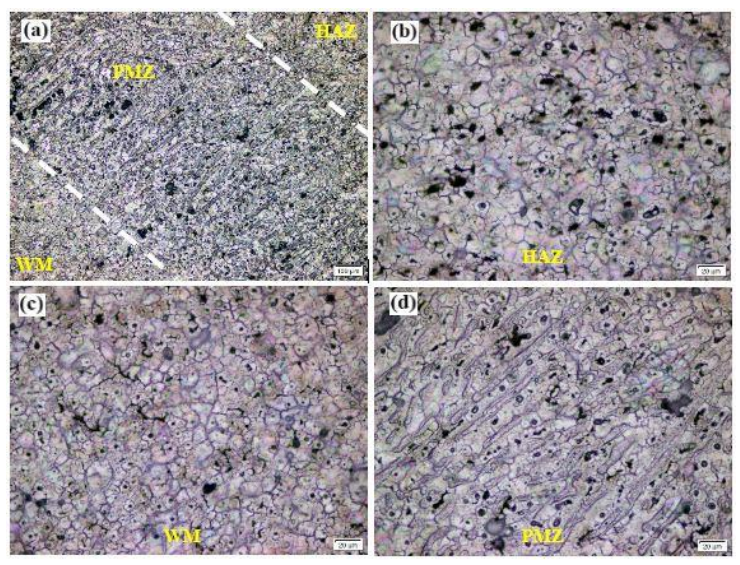

Fig. 8. Microstructure of different zones of welded specimen (53DS-NP).

\section{Conclusions}

An experimental study has been performed in order to investigate the effects of welding current and purging gas on mechanical properties and microstructure of tungsten inert gas welded aluminum alloy $5083 \mathrm{H} 116$. The results are summarized as follows:

- The UTS value and hardness of the welded joints decreased with the increase of welding current where the highest tensile (316 MPa) of the welded joints, $87 \%$ of that of the base metal, was produced when the welding current was $53 \mathrm{~A}$ and the hardness of welding joints decreased $6.62 \%$ for the lowest hardness in welded area.

- One side welding sequence is slightly better than the double sided one for the tensile and hardness results due to the heat addition effects of the two pass welding.

- The ultimate tensile strength and hardness of welded joint decreased with the addition of purging gas because argon offers more available heat than ambient air.

- Higher TIG current and double sided welding sequence produced broader PMZ area causing the grains of $\mathrm{PMZ}$ roughened and then decreasing the hardness in partially melted zone.

\section{References}

1. Gadewar S., Swaminadhan P., and Harkare M, Experimental investigations of weld characteristics for a single pass TIG welding with stainless steel, J. of Engineering and Technology. 2(8), 3676-3686, (2010)

2. Tarang Y S, and Yang W H, Int. J. Adv. Manuf. Technol. 14, 549 (1998)

3. Anil Kumar Bodukuri, K. Eswaraiah, Katla Rajendar, Siddartha A, Comparison of Aluminum Alloy 5083 properties on TIGW and FSW Processes, Materials Today: Proceeding 4, pp. 10197 - 10201, (2017)

4. Dongsheng Wu, Xueming Hua, Fang Li, Lijin Huang, Understanding of spatter formation in fiber laser welding of 5083 aluminum alloy, Int. J. of Heat and Mass Transfer, 113730 - 740, (2017)

5. M. Mazar Atabaki, N. Yazdian, R. Kovacevic, Partial penetration laser-based welding of aluminum alloy(AA 5083-H32), (Optik 127 67826804) (2016)

6. B. Chang, C. Allen, J. Blackburn, P. Hilton, Thermal and fluid flow characteristics and their relationships with porosity in laser welding of AA5083, Phys. Procedia 41 478-487, (2013)

7. K Vinod, Optimization of weld bead width in Tungsten Inert Gas welding of austenitic SS alloy, American J. of Mech. Eng. 2(2), 50-53, (2014)

8. Patel L. S. and Patel T. C., Optimization of welding parameters for TIG welding of 304L SS using Taguchi Approach, IJEDR, 2(1), ISSN: 2321-9939, 20, 1165-1170, (2014)

9. R Kumar, S Chattopadhyaya, S. Kumar, Influence of Welding Current on Bead Shape, Mechanical and Structural Property of Tungsten Inert Gas Welded Stainless Steel Plate, 4th International Conference on Materials Processing and Characterization, Materials Today: Proceedings 23342 - 3349, (2015)

10. A. R. Kumar, S. Varghese, M. Sivapragash, A Comparative Study of the Mechanical Properties of Single and Double Sided Friction Stir Welded Aluminium Joints, ICMOC-2012, Procedia Engineering 383951 - 3961, (2012)

11. Y Lianga, J Shena, S Hua, H Wanga, J Panga Effect of TIG current on microstructural and mechanical properties of 6061-T6 aluminium alloy joints by TIG-CMT hybrid welding J. of Materials Processing Tech., 255 161-174, (2018)

12. S. J. Barnesa, A. Steuwer, S. Mahawish, R. Johnson, P.J. Withers, Residual strains and microstructure development in single and sequential double sided friction stir welds in RQT-701 steel, Materials Science and Engineering A, 492 35-44 J.B. (2008)

*Corresponding author: ekakn@ymail.com 